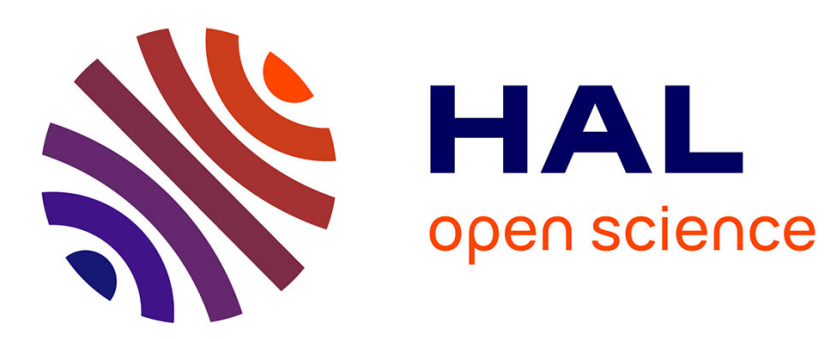

\title{
Configural information in gender categorisation
}

Jean-Yves Baudouin, G. W. Humphreys

\section{To cite this version:}

Jean-Yves Baudouin, G. W. Humphreys. Configural information in gender categorisation. Perception, 2006, 35 (4), pp.531-540. 10.1068/p3403 . hal-00561000

\section{HAL Id: hal-00561000 https://u-bourgogne.hal.science/hal-00561000}

Submitted on 15 Apr 2011

HAL is a multi-disciplinary open access archive for the deposit and dissemination of scientific research documents, whether they are published or not. The documents may come from teaching and research institutions in France or abroad, or from public or private research centers.
L'archive ouverte pluridisciplinaire HAL, est destinée au dépôt et à la diffusion de documents scientifiques de niveau recherche, publiés ou non, émanant des établissements d'enseignement et de recherche français ou étrangers, des laboratoires publics ou privés. 


\title{
Configural information in gender categorisation
}

\author{
Jean-Yves Baudouin\&Glyn W Humphreys
}

\begin{abstract}
The role of configural information in gender categorisation was studied by aligning the top half of one face with the bottom half of another. The two faces had the same or different genders. Experiment 1 shows that participants were slower and made more errors in categorizing the gender in either half of these composite faces when the two faces had a different gender, relative to control conditions where the two faces were nonaligned or had the same gender. This result parallels the composite effect for face recognition (Young et al, 1987 Perception $16747^{\wedge}$ 759) and facial-expression recognition (Calder et al, 2000 Journal of Experimental Psychology: Human Perception and Performance 26527 ^ 551). Similarly to responses to face identity and expression, the composite effect on gender discrimination was disrupted by inverting the faces (experiment 2). Both experiments also show that the composite paradigm is sensitive to general contextual interference in gender categorisation.
\end{abstract}

\section{Introduction}

The crucial role of configural information has been extensively demonstrated in studiesof face recognition (for a review, see Hancock et al 2000; Rakover 2002), and also in theprocessing of other types of facial information, such as emotional expression (eg Calderet al 2000). The decrease in performance observed when the configuration of the faceis not accessible or is altered has led many authors to conclude that the processing ofconfigural and/or relational information is at the heart of human expertise for faceprocessing (eg Carey and Diamond 1977; Davidoff 1986). Configural information refersto the information about the relations between facial components, and it includes bothfirst-order relations, which refer to the relative positions of the features (eg the eyesabove the nose), and second-order relations, which refer to the distance between thefeatures (eg close or distant eyes). This information is contrasted with local informationwhich refers to the properties of individual parts, the texture, or the colour of theelements.One of the most famous demonstrations of the dominance of configural informationin face recognition is the Margaret Thatcher illusion (Thompson 1980). When the eyesand the mouth are inverted within an upright normal face, this face looks monstrous. However, on viewing this upside-down, the monstrous aspect disappears and it is muchmore difficult to see the altered features. This illusion is interpreted as illustrating theimportance of configural information in face processing, with inverted features beingdistorted relative to the configural context of the upright face. The effect is reducedwhen faces are turned upside-down because configural information is less salient ininverted faces (see Bartlett and Searcy 1993). More generally, configural informationin facial-information processing has been extensively studied by comparing performance for normal upright versus upside-down faces (see Rakover 2002; Valentine 1988). Inversion affects many aspects of face recognition, includingidentity matchingfor unfamiliar faces, 
familiarity and semantic decisions, and famous-face recognition (eg Bruyer et al 1993; Rock 1974; Valentine 1991; Valentine and Bruce 1986, 1988; Yin 1969). Inversion effects can be reduced in children (Flin 1985) or even eliminated(Carey and Diamond 1977; Carey et al 1980). The effect also disappears after damage tothe right hemisphere (Yin 1970), or when faces are presented in the right visual field(Leehey et al 1978). Inversion appears to affect particularly the perception of distancerelations between facial features (Bartlett and Searcy 1993; Leder and Bruce 1998, 2000;Leder et al 2001; Searcy and Bartlett 1996). It may also disrupt the processing of otherkinds of facial information, including gender (Bruce et al 1993; Bruce and Langton 1994;Bruyer et al 1993).In other studies, evidence for the involvement of configural processing comes fromdifferences between performance when face parts and whole faces are presented. Forexample, the recognition of a specific feature (eg nose) can be better when it is pre-sented in a normal full face (eg Davidoff and Donnelly 1990; see also Tanaka andFarah 1993). In contrast, whole faces can disrupt performance when the task is toattend to face parts. Young et al (1987) combined the top part of a famous face withthe bottom part of another. When both parts were perfectly alignedöcreating a newcomposite faceörecognition from the part faces was more difficult than when thefaces were misaligned.When the faces were inverted, this disruptive effect of the wholeface was no longer significant. Calder et al (2000) reported a similar composite effectin the recognition of facial emotion: the emotion of each half part was more difficultto recognise when the other part displayed another emotion and was aligned. Again,this effect disappeared with face inversion.In the present paper, we extend the composite-face effects reported by Young et al(1987) in face recognition, and by Calder et al (2000) in emotion recognition, to gendercategorisation. Previously, the role of configural information in gender categorization has been demonstrated with the inversion paradigm (Bruce et al 1993; Bruce andLangton 1994; Bruyer et al 1993). These studies show that configural information canprovide an important cue for gender, since decreasing the salience of configural infor-mation (by inversion) reduces performance. However, the inversion paradigm does notprovide a test of whether gender categorisation is disrupted when inappropriate config-ural cues are present. In this paper we test for the effect of such cues, using thecomposite-face procedure. In this paradigm, a new facial configuration is created bythe alignment of two halves of different faces. Thus, configural information is notdisrupted (unlike when faces are inverted) but it can be ambiguous for the task (eg iffemale and male faces are combined, in a gender categorisation task). By testing forinterference from this new configural information, we learn something about the priorityof configural processing in a particular task; disruption from a face composite shouldonly come about if configural cues have greater priority than the processing of localparts and features.This last point is particularly important for understanding the task of genderclassification. Many studies have shown that some specific features (ie particular localcues) play an important role in gender categorisation. They include the eyebrows(Brown and Perrett 1993; Yamaguchi et al 1995) and the distance between the eye-brow and the eyelid (Campbell et al 1999), the face outline (Yamaguchi et al 1995), andthe jaw (Brown and Perrett 1993). Yamaguchi et al (1995) also found that 
changingonly two featuresöthe eyebrows and the face outlineöreversed the categorization from one gender to the other. The question, then, is whether configural information is just one gender cue among others, or if configural information plays a more dominantrole in gender categorisation than local feature cues (making gender categorization similar in this respect to recognising facial identities and emotions).To address this issue, a first experiment was designed to test whether a compositeeffect can be observed in gender categorisation (cf Calder et al 2000; Young et al1987). In this study, participants had to decide whether the top or bottom halves offaces were female or male faces. The other half faces could either have the same or adifferent gender, and the two halves were either aligned or nonaligned. If configuralinformation is dominant, then there should be interference from an irrelevant half faceof the opposite gender. Moreover, this should occur when the halves are aligned andnot when they are nonaligned.

\section{Experiment 1}

\subsection{Method}

\subsubsection{Participants.}

Sixteen individuals (fifteen females and one male) volunteered. Theywere aged between 18 and 25 years (mean . 19:9 years). All had normal or corrected-to-normal vision.

\subsubsection{Material.}

We used colour photographs of ten women (aged from 19 to 30 years) andten men (aged from 20 to 28 years). Each face was placed in a surrounding oval in orderto conceal information about the hairstyle and the top part of the body. The size ofthe oval was 381 pixels in width6500 pixels in height. Top and bottom versions werebuilt by cutting the oval across the middle, corresponding to location of the bridge ofthe nose. The top and bottom parts of these faces were presented to a control groupof eight subjects who had to judge whether each part belonged to a woman or to aman. For each part, at least seven to eight subjects correctly categorised the gender.Each face was linked to two other faces, one of the same gender and one of theopposite gender. Composite and noncomposite faces were then built by horizontallyabutting the top/bottom part of a face with the bottom/top part of each linked face(see figure 1 for an illustration). In this way we built 40 composite and 40 noncompo-site faces, of which one quarter corresponded to two women, one quarter to two men,one quarter to a woman at the top and a man at the bottom, and one quarter to a manat the top and a woman at the bottom. The faces of two other women and two men werealso used to build composite and noncomposite faces for the training session.

\subsubsection{Procedure.}

A trial started with the presentation of a fixation cross $(500 \mathrm{~ms})$ followed by a blank screen (500 ms). The target face then appeared and remained untilthe subject responded. The 40 
composite and 40 noncomposite faces were presentedtwo times in two distinct sessions. In the first session, half the subjects had to respondas accurately and as fast as possible if the top part was a woman or a man; the othersubjects responded to the bottom part. In the second session, the subjects performedthe reverse task. The part to which subjects responded was always presented at thecentre of the screen in the horizontal axis. For the noncomposite faces, the other partwas shifted to the right for half the trials in each experimental condition, and to theleft for the other half. The side towards which the shift was made was alternatedbetween participants.

\subsection{Results}

There were three within-subjects factors: gender of the other part (same versus different), type of face (composite versus noncomposite), and part for decision (top versus bottom).The dependent variables were latency for correct response and percentage of errors.For latency, responses to more than 2 standard deviations from the mean in eachcondition were not included. The errors were analysed to ensure that participants didnot use different strategies according to the type of the face. These analysesalso allowed us to assess if any interference was limited to response time or whetherinterference effects were also present in participants making the wrong response tothe gender of the correct facial part. Two three-factor analyses of variance (part for decision6gender of the other part6type of face) were carried out on the latency anderror data. The means and standard errors for correct response times and accuracy inthe various conditions are presented in table 1.

\subsubsection{Response times (RTs).}

There was a main effect of gender of the other part;participants responded faster when the other part was of the same gender [819 mswhen the other part was of same gender versus 914 ms when the other part was ofdifferent gender (F1 15. 24:68, p 5 0:001)]. The main effect of type of face was significant: 


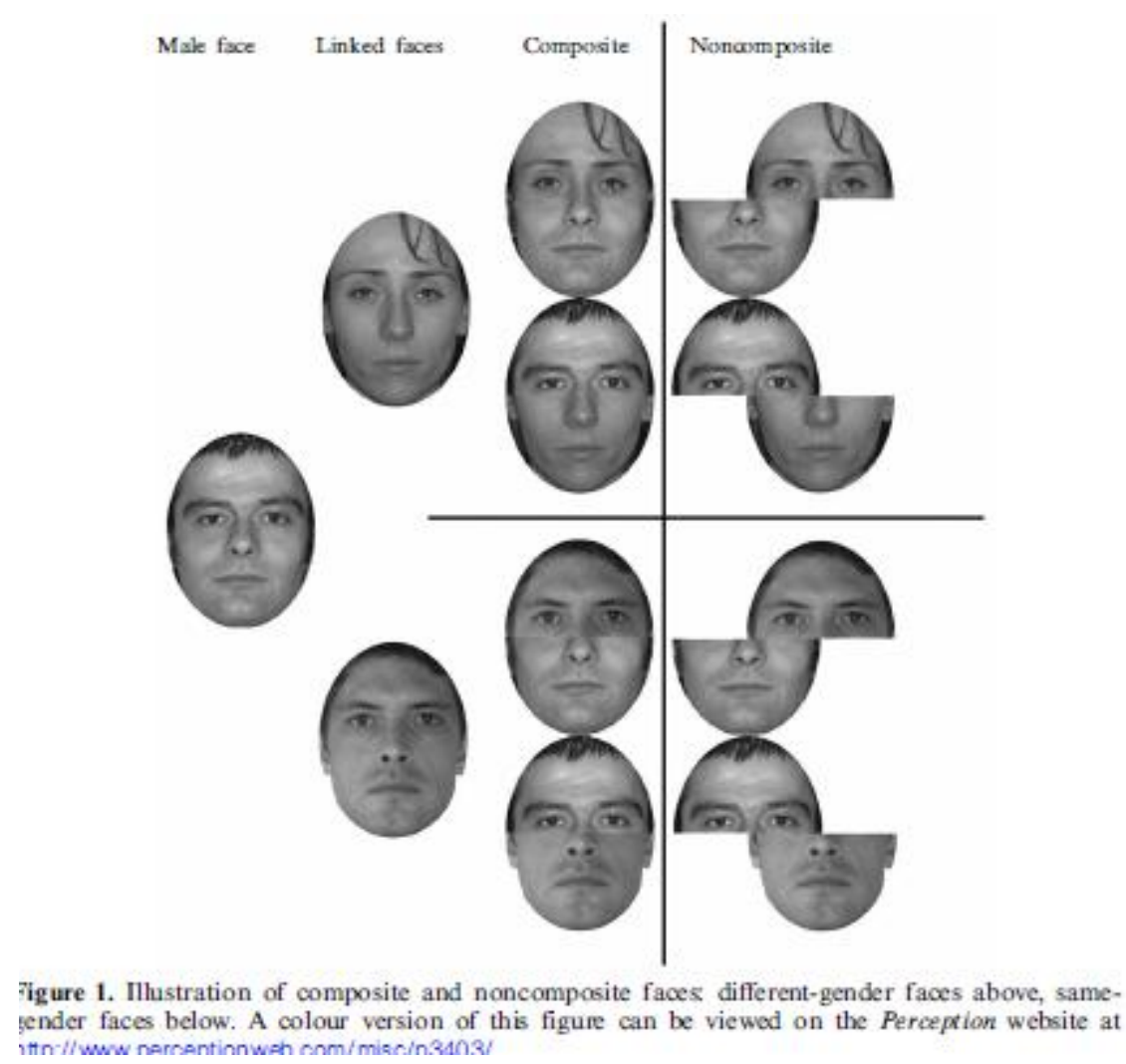

Table 1. Mean latencies for correct responses and error rates according to the part for decision, the type of face, and the gender of the other part. Standard errors are shown in parentheses.

\begin{tabular}{|c|c|c|c|c|c|c|c|c|}
\hline \multirow{3}{*}{$\begin{array}{l}\text { Latency } \\
\text { and } \\
\text { error rate }\end{array}$} & \multirow{2}{*}{\multicolumn{2}{|c|}{$\frac{\text { Bottom part }}{\text { composite }}$}} & \multicolumn{4}{|l|}{ Top part } & & \multirow[b]{3}{*}{$\begin{array}{l}\text { same } \\
\text { gender }\end{array}$} \\
\hline & & & \multicolumn{2}{|c|}{ noncomposite } & \multicolumn{3}{|c|}{ composite noncomposite } & \\
\hline & $\begin{array}{l}\text { different } \\
\text { gender }\end{array}$ & $\begin{array}{l}\text { same } \\
\text { gender }\end{array}$ & $\begin{array}{l}\text { different } \\
\text { gender }\end{array}$ & $\begin{array}{l}\text { same } \\
\text { gender }\end{array}$ & $\begin{array}{l}\text { different } \\
\text { gender }\end{array}$ & $\begin{array}{l}\text { same } \\
\text { gender }\end{array}$ & $\begin{array}{l}\text { different } \\
\text { gender }\end{array}$ & \\
\hline $\mathrm{RT} / \mathrm{ms}$ & $1071(85)$ & $878(64)$ & $821(41)$ & $803(40)$ & $966(57)$ & $831(47)$ & $798(36)$ & $764(36)$ \\
\hline Error $/ \%$ & $7.5(1.6)$ & $2.2(1.3)$ & $5.9(1.5)$ & $2.2(0.9)$ & $10.3(1.8)$ & $1.9(0.8)$ & $2.5(0.9)$ & $2.5(0.9)$ \\
\hline
\end{tabular}

composite faces were responded to more slowly $(937 \mathrm{~ms}$ for composite versus 796 msfor noncomposite faces (F1 15. 23:82, p 5 0:001). The interaction between type offace and gender of the other part was also significant (F1 15. 9:96, p 5 0:01). An effectof same ${ }^{\wedge}$ different gender occurred for composite faces [1018 ms with different genderversus $855 \mathrm{~ms}$ with same gender (F1 15. 18:35, p 5 0:001)], but not for noncompositefaces (F1 15. 3:09, p 4 $0: 05)$. RTs were longer for composite than for noncomposite faceswhen the gender differed between the two half-faces (1018 ms versus 809 ms, respectively,difference . 209 ms; F1 15. 25:24, p 5 0:001), and also, but to a lesser extent, whenthe gender was the same (855 ms versus $783 \mathrm{~ms}$, respectively, difference $72 \mathrm{~ms} ; \mathrm{F1} 15.5: 86$, p 5 0:05). Finally, the face part used for the decision had no effect either alone (F1 15. 1:75) or in interaction with other factors (part for decision6typeof face: F1 15. 1:16, part for decision6gender of the other part: F1 15. 0:38, overallinteraction: F1 15. 2:20). 


\subsubsection{Errors.}

The main effect of gender of the other part was significant: participantswere less accurate when the gender of the other part was different rather than thesame $(6.6 \%$ versus $2.2 \%$, respectively; F1 15. 39:73, p 5 0:0001). The main effect oftype of face was also significant: participants made more errors for composite faces(5.5\% for composite versus $3.3 \%$ for noncomposite faces; F1 15. 12:05, p 5 0:01). Theinteraction between type of face and gender of the other part was also significant(F1 15. 9:80, p 5 0:01), but this was qualified by an interaction between type of face,gender of the other part, and part for decision (F1 15. $4: 95$, p 5 0:05). The interactionbetween type of face and gender of the other part was significant when the decisionwas to the top (F1 15. 12:79, p 5 0:01), but not when the decision was to the bottom(F1 15. 0:57). When the decision was to the top, an effect of same ${ }^{\wedge}$ different genderoccurred for composite faces $(10.3 \%$ with different gender versus 1.9\% with samegender; F1 15. 21:74, p 5 0:001), but not for noncomposite faces (F1 15. $0: 00)$. Errorswere more frequent for composite than for noncomposite faces when the genderdiffered between the two half-faces (10.3\% versus $2.5 \%$, respectively; F1 15 . 14:67,p 5 0:01), but not when it was the same (F1 15. 0:48). When the decision was to thebottom part, the main effect of gender of the other part was significant; participantsmade more errors when the other part was of opposite gender (6.7\% with differentgender versus $2.2 \%$ with the same gender; F1 15. 14:48, p 5 0:01).

\subsection{Discussion}

The results suggest that there is configural processing of the gender of faces whichinterferes in the processing of facial parts. Participants were slower to process thegender of a half-face when it was aligned with another face of the opposite gender,than when the opposite face was shifted or when there was an aligned face of the samegender. This observation parallels those by Calder et al (2000) and Young et al (1987)for expression recognition and face recognition, respectively. The results cannot beaccounted for in terms of an Eriksen-type interference effect when face parts areresponse-incompatible (ie a conflict in the response to the two partsöEriksen andEriksen 1974), since the incongruity effect arose strongly in the composite condition.In other words, both parts had to be aligned, thus creating a new facial configuration,to generate maximal interference. Consequently, the results of experiment 1 indicatethat configural information plays an important role in gender categorisation. Even ifsubjects rely on specific facial features to realise the task (eg eyebrow shape anddensity for the top half, facial texture and chin shape for the bottom half ), it is clearthat perturbation of the configuration by adding features of the opposite gender to afacial composite increased response latency. The alignment of both parts appeared tocreate a new configuration, with an ambiguous gender, when both parts were of opposite gender. This ambiguity interfered with the categorisation of each, unambiguous, part.Nevertheless, an interference effect also occurred for same-sex faces shown ascomposites rather than noncomposites: RTs were slower to composites than to noncom-posites. This may again reflect a contribution of a new 
facial 'Gestalt' when the faceswere aligned. In this Gestalt, there may be a lack of correlation between the gender-related features in the top and bottom halves of the face, slowing RTs. We also foundthat more errors occurred when the decision was to the bottom part and the top partwas of different gender, whatever the composite versus noncomposite type of face.We return to this point in section 4.To ensure that the composite effect did really result from configural information,Young et al (1987) as well as Calder et al (2000) replicated their experiments by con-trasting upright stimuli with upside-down ones. Configural information is assumed tobe less salient when faces are inverted than when they are upright (Yin 1969). Anyinterference consequent on the facial configuration should at least reduce with invertedfaces, and this is what Calder et al and Young et al reported. Experiment 2 wasdesigned to test whether the same pattern of results occurs in a gendercategorisationtask. The same stimuli were presented to a new group of participants in two conditions: upright or upside-down. If configural information is crucial, the composite effectfor gender categorisation should be present with upright, but not with upsidedownfaces.

\section{Experiment 2}

\subsection{Method}

\subsubsection{Participants.}

Sixteen people (fifteen females and one male) volunteered. They wereaged between 18 and 22 years (mean . 19:7 years). All had normal or corrected-to-normal vision.

\subsubsection{Material.}

We used the same material as in experiment 1.

\subsubsection{Procedure.}

The procedure was the same as in experiment 1, except that participantsperformed four sessions. Two sessions were identical to experiment 1 . The two otherswere identical on all points except that the stimuli were presented upside-down. Halfthe participants performed the two sessions (top and bottom) with upright facesfirst; the other half performed the two sessions with upside-down faces first. The orderof top versus bottom sessions was alternated between participants.

\subsection{Results}

The factors analysed were orientation (upright versus upside-down), gender of theother part (same versus different), type of face (composite versus noncomposite), and part for decision (top versus bottom). All these factors were manipulated withinsubjects. The dependent variables were latency of the correct response and error rate. For latency, responses to more than 2 standard deviations from the mean in eachcondition were not included. The means 
and standard errors for correct response timesand accuracy in the various conditions are presented in table 2. Two four-factor analyses of variance (orientation6part for decision6gender of the other part6type offace) were carried out on the latency and error data.

\subsubsection{RTs.}

The main effect of orientation was significant: participants responded fasterto upright than to upside-down faces (816 ms versus 918 ms; F1 15. 16:37, p 5 0:01).The main effect of gender of the other part was significant: participants respondedfaster when the other part was of the same gender ( $854 \mathrm{~ms}$ when the other part wasof same versus $880 \mathrm{~ms}$ when the other part was of different gender; F1 15. 7:80,p 5 0:05). There was also a main effect of type of face: composite faces wereresponded to more slowly (890 ms for composite versus 845 ms for noncompositefaces; F1 15 . 19:26, p 5 0:001). There was a significant interaction between gender ofthe other part and orientation (F1 15 . 16:20, p 5 0:01), but it was qualified by asignificant interaction between type of face, gender of the other part, and orientation(F1 15. 8:39, p 5 0:05). There was an interaction between type of face and gender ofthe other part when the faces were upright (F1 15. 5:27, p 5 0:05). This did not occurwhen the faces were upside-down (F1 15. 0:07). When the faces were upright, an effectof same ${ }^{\wedge}$ different gender occurred for composite faces (890 ms with different genderversus $774 \mathrm{~ms}$ with same gender; F1 15. 12:68, p 5 0:01), but not for noncompositefaces (F1 15. 0:01). RTs were longer for composite than for noncomposite faces whenthe gender differed between the two half-faces (890 ms versus 799 ms, respectively;F1 15. 7:07, p 5 0:05), but not when it was the same (F1 15. 1:65).

Table 2. Mean latencies for correct responses and error rates according to the orientation, the part for decision, the type of face, and the gender of the other part. Standard errors are shown in parentheses.

\begin{tabular}{|c|c|c|c|c|c|c|c|c|}
\hline \multirow{3}{*}{$\begin{array}{l}\text { Latency } \\
\text { and } \\
\text { error rate }\end{array}$} & \multicolumn{2}{|c|}{ Bottom part } & \multicolumn{4}{|l|}{ Top part } & & \\
\hline & \multicolumn{2}{|l|}{ composite } & \multicolumn{2}{|c|}{ noncomposite } & \multicolumn{2}{|l|}{ composite } & \multicolumn{2}{|c|}{ noncomposite } \\
\hline & $\begin{array}{l}\text { different } \\
\text { gender }\end{array}$ & $\begin{array}{l}\text { same } \\
\text { gender }\end{array}$ & $\begin{array}{l}\text { different } \\
\text { gender }\end{array}$ & $\begin{array}{l}\text { same } \\
\text { gender }\end{array}$ & $\begin{array}{l}\text { different } \\
\text { gender }\end{array}$ & $\begin{array}{l}\text { same } \\
\text { gender }\end{array}$ & $\begin{array}{l}\text { different } \\
\text { gender }\end{array}$ & $\begin{array}{l}\text { same } \\
\text { gender }\end{array}$ \\
\hline \multicolumn{9}{|l|}{ Upright: } \\
\hline $\mathrm{RT} / \mathrm{ms}$ & $954(98)$ & $799(60)$ & $823(59)$ & $815(68)$ & $827(76)$ & 749 (64) & $776(76)$ & $789(75)$ \\
\hline Error $/ \%$ & $11.9(1.8)$ & $4.7(1.3)$ & $6.3(1.6)$ & $4.7(1.3)$ & $15.3(2.7)$ & $3.8(1.1)$ & $4.1(1.4)$ & $3.1(0.9)$ \\
\hline \multicolumn{9}{|c|}{ Upside-down: } \\
\hline $\mathrm{RT} / \mathrm{ms}$ & $1030(107)$ & $1041(105)$ & $928(86)$ & $911(81)$ & $869(87)$ & $851(78)$ & $839(78)$ & $876(88)$ \\
\hline Error $/ \%$ & $19.1(2.1)$ & 13.4 (1.6) & $18.1(2.3)$ & $13.1(1.8)$ & $8.8(1.3)$ & $6.3(1.3)$ & $9.1(1.3)$ & $8.1(1.3)$ \\
\hline
\end{tabular}

The main effect of part for decision was significant: participants responded fasterto the top than to the bottom part (822 ms versus 912 ms; F1 15. 16:55, p 5 0:01).This effect was qualified by type of face and part for decision interaction (F1 15. 6:49,p 5 0:05); when the decision was to the bottom part, RTs were slower for compositefaces (956 ms for composite versus 869 ms for noncomposite faces; F1 15. 12:49,p 5 0:01). The difference was not 
significant when the decision was to the top part(F1 15. 0:12). The effect of part for decision was also qualified by an interactionbetween gender of the other part and part for decision (F1 15. 9:09, p 5 0:05): whenthe decision was to the bottom part, RTs were slower when the other part was ofdifferent gender (933 ms when the other part was of different versus 891 ms when theother part was of same gender; F1 15. 9:89, p 5 0:01). The difference was not signifi-cant when the decision was to the top part (F1 15. 2:26). These effects were notqualified by orientation (part for decision6orientation: F1 15. 2:13; part for decision6gender of the other part6orientation: F1 15. 0:56; part for decision6type offace6orientation: F1 15. 3:53; overall interaction: F1 15. 3:22).

\subsubsection{Errors.}

The main effect of orientation was significant: participants made moreerrors for an upsidedown than for an upright face (12\% versus 6.7\%; F1 15. 43:82,p 5 0:0001). The main effect of gender of the other part was significant: participantsmade more errors when the other part was of different gender (11.6\% versus $7.1 \%$ when the other part was of same gender; F1 15 . 33:35, p 5 0:0001). The main effect oftype of face was significant: participants made more errors for composite than fornoncomposite face (10.4\% versus 8.3\%; F1 15 . 7:62, p 5 0:05). The main effect of partfor decision was significant: participants made more errors to the bottom than to thetop part (11.4\% versus 7.3\%; F1 15 . 11:49, p 5 0:01). The interactions between orientation and type of face (F1 15. 10:09, p 5 0:01)and between gender of the other part and type of face (F1 15. 16:36, p 5 0:01) weresignificant. The interaction between type of face, gender of the other part, and orientation was also reliable (F1 11. 19:64, p 5 $0: 01)$. This last effect arose because theinteraction between type of face and gender of the other part was significant whenfaces were upright (F1 15. 29:82, p 5 0:0001), but not when they were upside-down(F1 15. 0:53). For upright faces, participants made more errors for composite faceswith a difference of gender relative to both (i) composite faces with the same gender(13.6\% versus 4.2\%; F1 15. 34:79, p 5 0:0001) and (ii) noncomposite faces withdifferent genders (13.6\% versus 5.2\%; F1 15. 25:37, p 5 0:001). The other conditionsdid not differ (all Fs 5 2:73). For upside-down faces, the effect of type of face was notsignificant (F1 15. 0:07), but the effect of gender of the other part was: participantsmade more errors when the other part was of different gender (13.4\% versus $10.2 \%$ when the other part was of same gender; F1 15. 8:24, p 5 0:05).The interaction between part for decision, orientation, and gender of the otherpart was also significant (F1 15. 11:43, p 5 0:001). Gender of the other part signifi-cantly interacted with orientation when the decision was to the top part (F1 15. 5:24,p 5 0:05), but not when it was to the bottom part (F1 15. 0:33). When the decisionwas to the top part, participants made more errors for upright faces when the bottom wasof a different rather than the same gender (9.7\% versus 3.4\%; F1 15. 19:74, p 5 0:001); there was no significant difference for upside-down faces (F1 15. 1:63). When thedecision was to the bottom part, participants made more errors when the top wasof a different rather than the same gender for both upright (9.1\% versus 4.7\%;F1 15. 17:93, p 5 
0:001) and upside-down faces (18.6\% versus 13.3\%; F1 15. 10:86,p 5 0:01).The overall interaction was not significant (F1 15. 0:93), and there were no othersignificant interactions.

\subsection{Discussion}

Overall, the results of experiment 2 matched those of experiment 1 , ie the presence ofopposite-gender faces interfered with gender categorisation when faces were upright,and this was significant only when both parts were aligned to create a new facialconfiguration. This configuration-based interference effect disappeared when faceswere upside-down, when the salience of configural information in the face is reduced.However, the interference effect for same-sex faces shown as composites rather thannoncomposites in experiment 1 was not replicated in experiment 2 . There was none-theless also another interference effect from different-gender faces that did not relyon the creation of a new configuration: participants were less accurate in recognizing the gender when the other part was of a different gender, whether the faces werecomposite or not. This effect disappeared with upside-down faces when the decisionwas to the top part, but not when the decision was to the bottom part.

\section{General discussion}

To recapitulate the results of both experiments, participants were slower and lessaccurate in categorising the top or bottom half of a face as female or male when theother part had a different gender and was aligned to create a new facial configuration. This interference effect disappeared when faces were inverted (experiment 2). Thisobservation indicates that configural information is an important cue to gendercategorisation, and that inappropriate configural information can interfere with theresponses based on local feature information.The results of both experiments also indicate that decisions to the gender ofthe bottom half part of a face are sensitive to interference from the top half part.This last observation did not result from a configural effect since it did not dependon the alignment of the two half parts. Moreover, it was also observed when faceswere upside-down, suggesting that the interference effect relies on facial propertieswhich are not disrupted by inversion. So, the composite paradigm is sensitive to gen-eral contextual interference in gender categorisation. Mainly, the top part of the faceinterfered in gender categorisation responses to the bottom part, and this effect didnot rely on the creation of a new configuration. This can be due to a particular weightof some of top features in gender categorisation. For example, the eye region and theeyebrows have frequently been reported as important cues to gender (eg Bruce et al1993; Campbell et al 1999; Yamaguchi et al 1995). It then appears that the singlepresentation of gender-specific features from the top part of a face interferes in thecategorisation of the gender of features from the top part of the face, whether they arealigned or not, and whatever the orientation of the two parts. This suggests that thesetop features are categorised automatically, and consequently interfere in the responseto bottom features. The reverse is not true. According to the literature, eyebrows aregood candidates to be these top features, since they are among the top features the 
most important in gender categorisation (see Brown and Perrett 1993).Overall then, the results of this study allow a better understanding of the mecha-nisms underlying the processing of gender of face. As discussed in section 1, previousstudies demonstrate the role of some distinct features in gender categorisation, including the eyebrows, jaw, or face outline (eg Brown and Perrett 1993; Yamaguchi et al1995). The results here show that configural information not only contributes in addition to any local features (eg Bruce et al 1993; Bruyer et al 1993), but that it is alsogiven high priority. Thus, inappropriate configural information disrupts the categorisa tion task. To account for the data, models of gender categorisation have to integrateconfigural information processing. Nevertheless, local information is not silent in gender categorisation, as top features are given stronger weighting than bottom features.This differs from studies of identity and facial expression judgments, where neitherYoung et al (1987) nor Calder et al (2000) found an interference effect from the top(or indeed either) part across the composite and nonaligned conditions. Hence, differentface tasks may 'weight' differently the contrasting properties of faces, though configuralinformation plays a role in each case.

\section{Acknowledgments}

This work was supported by an MRC grant to $G$ W Humphreys and a fellowshipfrom the Fondation FYSSEN to J-Y Baudouin.

\section{References}

Bartlett J C, Searcy J, 1993 "Inversion and configuration of faces" Cognitive Psychology $25281 \wedge 316$

Brown E, Perrett D I, 1993 “"What gives a face its gender?" Perception 22829 ^ 840

Bruce V, Burton A M, Hanna E, Healey P, Mason O, Coombes A, Fright R, Linney A, 1993 “'Sex discrimination: how do we tell the difference between male and female faces?" Perception22 $131^{\wedge} 152$

Bruce V, Langton S, 1994 "The use of pigmentation and shading information in recognizing thesex and identity of faces" Perception $23803 \wedge 822$

Bruyer R, Galvez C, Prairial C, 1993 "Effect of disorientation on visual analysis, familiaritydecision and semantic decision on faces" British Journal of Psychology $84433 \wedge$ 441

Calder A J, Young A W, Keane J, Dean M, 2000 "Configural information in facial expressionperception" Journal of Experimental Psychology: Human Perception and Performance $26527^{\wedge} 551$ 
Campbell R, Benson P J, Wallace S B, Doesbergh S, Coleman M, 1999 "More about brows:How poses that change brow position affect perceptions of gender" Perception 28 $489 \wedge 504$

Carey S, Diamond R, 1977 "From piecemeal to configurational representation of faces" Science195 $312 \wedge 314$

Carey S, Diamond R, Wood B, 1980 "The development of face recognition: A maturationalcomponent?" Developmental Psychology $16257^{\wedge} 269$

Davidoff J B, 1986 “'The specificity of face perception: Evidence from psychological investigations", in The Neuropsychology of Face Perception and Facial Expression Ed. R Bruyer(Hillsdale, NJ: Lawrence Erlbaum Associates) pp $147^{\wedge} 166$

Davidoff J B, Donnelly N, 1990 "Object superiority: A comparison of complete and part probes"Acta Psychologica $73222^{\wedge} 243$

Eriksen B A, Eriksen C W, 1974 "Effects of noise letters upon the identification of a target letterin a non-search task" Perception \& Psychophysics 16143 ^ 149

Flin R H, 1985 "Development of face recognition: An encoding switch?" British Journal ofPsychology $76123 \wedge 134$

Hancock P J, Bruce V, Burton A M, 2000 "Recognition of unfamiliar faces" Trends in CognitiveSciences $4330^{\wedge} 337$

Leder H, Bruce V, 1998 "Local and relational aspects of face distinctiveness" Quarterly Journalof Experimental Psychology A $51449 \wedge 473$

Leder $H$, Bruce V, 2000 "When inverted faces are recognized: the role of configural informationin face recognition" Quarterly Journal of Experimental Psychology A 53513 ^ 536

Leder H, Candrian G, Huber O, Bruce V, 2001 "Configural features in the context of uprightand inverted faces" Perception $3073^{\wedge} 83$

Leehey S, Carey S, Diamond R, Cahn A, 1978 "Upright and inverted faces: The right hemisphereknows the difference" Cortex $14411 \wedge 419$

Rakover S S, 2002 "Featural vs. configural information in faces: A conceptual and empiricalanalysis" British Journal of Psychology $931^{\wedge} 30$

Rock I, 1974 “'The perception of disoriented figures" Scientific American 230(1) 78 ^ 85

Searcy J H, Bartlett J C, 1996 "Inversion and processing of component and spatialrelationalinformation in faces" Journal of Experimental Psychology: Human Perception and Performance22 $904 \wedge 915$ 
Tanaka J W, Farah M J, 1993 "Parts and wholes in face recognition" Quarterly Journal of Exper imental Psychology A 46225 ^ 245

Thompson P, 1980 “Margaret Thatcher: a new illusion" Perception 9483 ^ 484

Valentine T, 1988 "Upside-down faces: A review of the effect of inversion upon face recognition"British Journal of Psychology $79471 \wedge 491$

Valentine T, 1991 "A unified account of the effect of distinctiveness, inversion, and race in facerecognition" Quarterly Journal of Experimental Psychology A 43161 ^ 204

Valentine T, Bruce V, 1986 "The effect of face, inversion and encoding activity upon face recogni-tion" Acta Psychologica 61259 ^ 273

Valentine T, Bruce V, 1988 “Mental rotation of face" Memory and Cognition 16556 ^ 566

Yamaguchi M K, Hirukawa T, Kanazawa S, 1995 "Judgment of gender through facial parts"Perception $24563^{\wedge} 575$

Yin R K, 1969 “Looking at upside-down faces" Journal of Experimental Psychology 81141 ^ 145

Yin R K, 1970 "Face recognition by brain-injured patients: A dissociable ability?" Neuropsychologia8 395 ^ 402

Young A W, Hellawell D J, Hay D C, 1987 "Configurational information in face perception"Perception $16747^{\wedge} 759$ 